\title{
Factors Influencing Academic Performance of Students in Blended and Traditional Domains
}

\author{
https://doi.org/10.3991/ijet.v13i02.8031 \\ Ahmed O. A. Ismail $\left({ }^{\varpi}\right)$ \\ Universiti Teknologi PETRONAS, Bandar Seri Iskandar, Malaysia \\ King Khalid University, Mohayel, Saudi Arabia \\ ibn_omer@hotmail.com \\ Ahmad K. Mahmood \\ Universiti Teknologi PETRONAS, Bandar Seri Iskandar, Malaysia \\ Abdelzahir Abdelmaboud \\ King Khalid University, Mohayel, Saudi Arabia
}

\begin{abstract}
This paper aims to identify the most important and significant factors in two different areas of learning: combined and traditional learning. Several critical issues have not yet been resolved to achieve the full potential of the learning outcomes in the two domains. The objective of this paper is to review the critical factors that have a great influence on academic performance. The document focuses specifically on a set of factors such as the use of technology, the interaction processes, the characteristics of the students and the class. These identified factors were classified and discussed. The document also determines the technical and pedagogical limitations of the two declared domains. The technical and pedagogical challenges were proposed and future works were recommended.
\end{abstract}

Keywords-Technology Use, Interaction Process, Student Characteristics, Class Characteristics, Blended Learning, Traditional Learning.

\section{Introduction}

The best learning environment has emerged with the combination of the strongest aspects of blended learning (BL) and traditional learning (TL). BL is adopted in the learning process to eliminate TL deficiencies and web-based learning (WB). TL is ineffective in terms of student participation and interaction process, that is full of a limited period of time and that distance learning limits the interaction between students has caused the emergence of this new learning environment [1].This new learning approach is $\mathrm{BL}$, in the international literature $\mathrm{BL}$ is referred to as hybrid learning and mixed learning and is also used very differently by many researchers, academics, and scientists. Online learning is deprived of many advantages that TL incorporates. The greatest shortcoming of online approaches is that they cannot provide students 
with opportunities for social interaction and face-to-face with other students and instructors [1].

There are some factors that prevent the future growth of online learning. These factors are represented in the management of online courses that require a lot of time. In addition, students are often frustrated. In addition, the problems cited with the use of technology, as well as the lack of communication between students and remote instructors. furthermore, some programs experience high dropout rates as a result[2]. Student academic performance (SAP) includes academic achievement, achievement of learning objectives, acquisition of desired skills and competencies, satisfaction, persistence, and post-university performance[3]. The term academic achievement refers to some method of declaring or expressing the academic rank of a student. In general, it is a grade for a course, an average for a group of courses in a particular subject, or an average for all courses expressed in a 0 to 100 or other quantitative scales[4]. In this paper, SAP was defined as a total grade of a student in a specific course that is distributed in the midterm marks and final exam scores and was expressed in a 0 to 50 scale for each midterm exam and the final exam. The objective of this work is to identify the factors that influence SAP in BL compared to TL.

There are many studies in the literature that discussed the influence of the use of TL and BL technologies on SAP as established in the Refs [5-9]. In addition, some studies focused on the influence of interaction processes in SAP in two different domains of TL and BL as established by Refs [10-14]. Furthermore, other studies presented the influence of the characteristics of students and classes in SAP as established in Refs [15-18]. However, none of these studies addressed the influence of all the factors established in SAP. Therefore, this study has classified the factors that influence SAP in four main factors. These factors are the use of technology (TU), the interaction process (IP), the characteristics of the student (SC) and the characteristics of the class (CC). Each main factor is further divided into subfactors. Figure 1 showed the factors that have a great influence on SAP in deliveries BL and TL.

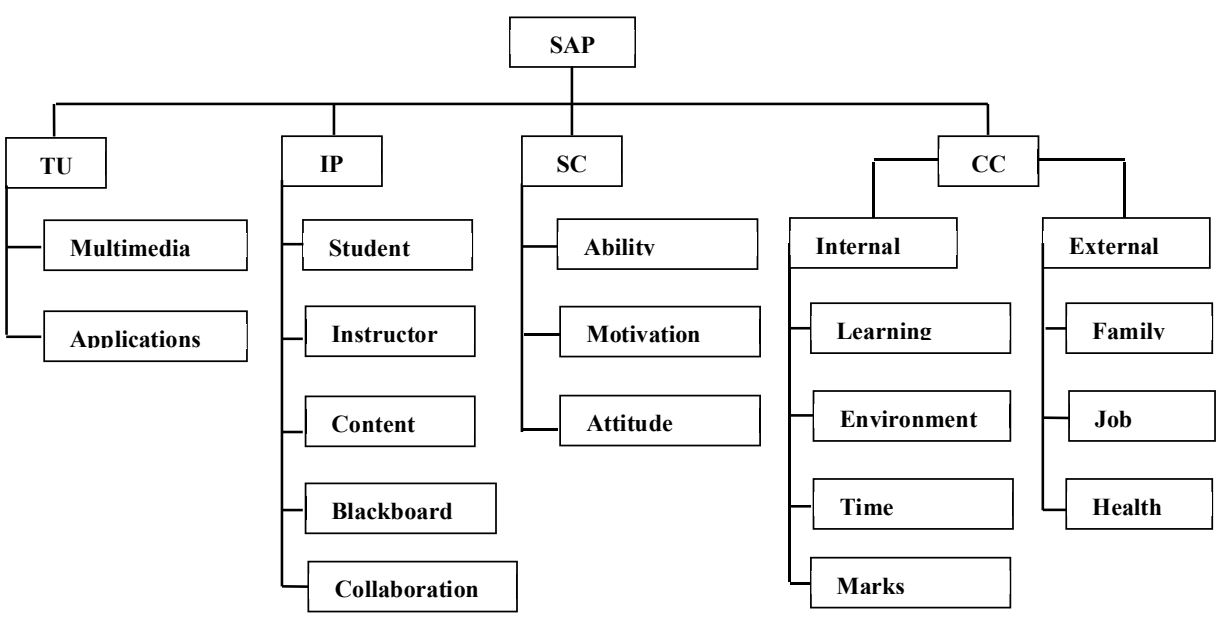

Fig. 1. Classification of Factors Influencing SAP in BL and TL 


\section{Factors influencing SAP in BL and TL deliveries}

The objective of this section is to identify the most important factors that have a great influence on academic performance in BL and TL deliveries.

\subsection{The influence of the use of technology on SAP}

The use of technologies in TL and BL includes multimedia technologies and applications that are used in teaching and learning processes. It involves skill and competence in the use of technology to carry out specific activities in BL and TL. Ref. [19] stated that the use of technology is not intended to replace the traditional classroom setting but to provide new opportunities and a new virtual environment for interaction and communication between students and their instructors. Ref. [20] explained that traditional lectures could be an effective way to help students acquire new knowledge, while the pace of instructors' lectures in the classroom sometimes causes problems. These problems are reported in some students who do not have new information or content and other students may feel that the same material is quite difficult to understand because they do not have sufficient prior knowledge about the subject.

The effect of the use of TL Technology on SAP - Ref [21] said the digital learning environment such as the Internet and the Web-based now defines the highly interactive learning environment redefinition as well as the concept of teaching. Classrooms are not the only place in a learning process. The whole world is the classroom. Millions of students from around the world belong to the network generation. Students can travel around the world with the click of a mouse or even at the command of their voice. Ref [5] noted that one of the internal class factors that have a great influence on academic performance is the technology used in classroom and exam systems. Ref [6] stated that students use computers and other digital media to entertain, learn and communicate. These students prefer interactive learning. This type of learning emphasizes the innovative approach such as learning discovery, studentoriented, manipulated materials, videotapes, slides, computer-assisted instruction. All of this interactive learning has become part of the innovative approach to classroom support.

The advance of technological support emphasized that combined learning rapidly evolves as an alternative to teaching and learning in higher education, which in turn contributes to distance education. In addition, TS offers a just-in-time approach to your new learning challenges. Ref [22] stated that the use of new multimedia technologies and the Internet to improve the quality of learning by facilitating access to resources and services, as well as remote exchange and collaboration will result in the improvement of learners academic performance. The collaborative technologies such as discussion forums, peer-tutoring and video conferencing have an effect on student learning as well as assist in achieving higher order thinking skills. Video conference technology is a system that supports transferring of information in the form of text, audio, and video, from one user to other users in different locations. Other technologies such as multi-user virtual environments (MUVE) capable of synchronous communication and are considered social networking applications. 
The effects of the use of BL Technology on SAP - Five studies in TS were used. The first study was carried out by Refs[23, 24] that studied the effects of LMS on student performance in relation to a web-based forum. Their results revealed that online questionnaires, assignments and the electronic content of the BLS had a significant effect on SAP, but the feeling of isolation in an online environment represents an obstacle factor that affects the attitude of students to use LMS. They also confirmed that there is a lack of interaction between students when using pure online.

The second study conducted by Ref [7], which states that students can interact with each other by using features of LMS in order to bridge the gap of lack of close interaction among students. This, in turn, is reflected in the SAP. Although online activities are used to foster two forms of interaction, however, this study attempts to use LMS activities as discussion forums in order to raise the level of student interaction processes. The third and fourth studies are carried by Refs[8, 9], who studied the effect of e-learning tools in SAP. Their findings revealed that the ease of use of learning tools will lead to improved academic performance. This study assumed that student interaction with the ease of use of LMS will increase students' motivation to participate effectively through well-designed BL courses.

The fifth study indicated that software is an important element of technology for enhancing the quality of technological resources. The software must provide a new experience to the students, leading them to a more active and collective engagement during the class. Ref [25] confirmed that Web 2.0 technologies are generally associated with a variety of meanings that include an emphasis on user-generated content, information sharing, collaborative efforts, new ways of interacting with Web-based applications as well as the use of the Web as a social platform for creating, repositioning and consuming content. Web 2.0 technologies include social networks, blogs, micro-blogs, wikis, discussion boards, bookmarking and media sharing.

One of the main objectives of using the combination of TL and BL domains is to examine the two different types of methods of these domains. In addition, it identifies which domains are positively associated with SAP. This article explores the effect of the interaction process when students use LMS activities in BL and the level of student interaction in SAP.

\subsection{The influence of interaction processes on SAP}

Interactions occur when objects and events mutually influence one another. An instructional interaction is an event that takes place between the student and the student's environment. Its purpose is to respond to the student in a way that aims to change their behavior towards an educational goal. Educational interactions have two purposes. The first is to change the students and the second is to move them towards the achievement of their goals. In this article, interaction refers to the response of students to students, students to instructors, and students to content.

Interaction can be divided into three types: (a) student-student interaction (S2SI), (b) student-instructor interaction (S2II) which refers to both forms of communication and c) interaction between students and content (S2CI). All these interactions occur synchronously or asynchronously through collaborative learning (CL). This study 
focuses on the fourth interaction between student and the blackboard interface (S2BI) that has been neglected and there are few studies challenging this type of interaction. Ref [26] classify online interactions into four types of interaction models: purpose/task, activity based, tool-based, and communication models. Purpose/task models categorize interactions in terms of their functionalities. Activity-based models classify interactions in terms of their instructional purposes. Tool based models group technology tools in terms of their capabilities in supporting educational interaction. Communication models that categorize interaction in terms of relationships or exchanges between learning parties. Ref [27] indicated that the interaction is related to the activity which has to be performed in a physical/virtual environment, for example, the interaction of instructor with students is taking place mainly in classroom, office or/and virtual classes. Also, students' interaction with course content can take place in the library or/and digital content.

The effect of student-to-student interaction on SAP - The objective of S2SI is to study the interaction between students in order to examine the effect of this interaction over SAP. The interaction between students can occur between one student to another, between one student to several other students or between two groups of students. S2SI is intended to stimulate and motivate students to learn the course content by exchanging dialogue between them. Ref [10] (p. 85) stated that students in an online learning environment lack opportunities to experience the benefits of both structured dialogue and the sense of community that can be created in the more traditional classroom environment. The lack of interaction in online educational environments is supposed to be avoided in order to make online educational environments similar to traditional classrooms environments that are filled with the vital learning interactivity. Ref [11] (p. 104) explained that S2SI is the exchange of information and ideas that occurs among students about the course in the presence or absence of the instructor. This type of interaction can take the form of group projects, or group discussion, etc. The S2SI can foster learning through student collaboration and knowledge sharing.

Ref [28] to study the relationship between online participation and student ratings. Their study showed that there is a lack of close interaction between students. This lack may have adverse consequences, possibly because students experience feelings of isolation. It makes sense that the more active a student is, the better he or she will perform. Ref $[7,24]$ suggested that students can interact with each other through discussion forums and course messages in order to bridge the gap of this lack of close interaction between students and feelings of isolation in an online environment. Neither the feeling of isolation nor the interaction in an online environment can bridge the gap between a problem of close interaction. However, the two forms of interaction between students and instructors can minimize this gap. Ref [7] stated that students can interact with each other by using features of learning management systems (LMS) in order to bridge the gap in the lack of close interaction between students. This, in turn, is reflected in the SAP as they have no other choice than to sustain with learning activities. This study attempts to examine the effect of the two forms of interaction in SAP. The objective of S2SI is to study the effect of these interactions on SAP. In BL delivery, the interaction between students helps them to exchange ideas and to share 
information between students as well as allow them to discuss their subjects matter through online discussion forums, chat rooms, and e-mail or course messages. On the other hand, in TL delivery students may interact in person and through electronic means (e.g. e-mail, telephone and facsimile machine). In other words, students can interact during class or schedule meetings outside the normal class hours. Ref [12] posed several challenges to implement the designed interaction that reflects a high level of student-student interaction in the online environment, including the size of the class, the time involved in evaluating student learning, motivation and the experience of collaborating using the technology.

The effect of student-to-instructor interaction on SAP - The objective of S2II is to study the two forms of interaction between students and instructors in order to examine the effect of these interactions over SAP. Also, S2II is intended to help reinforce student understanding of the material or explain meanings. Moreover, S2II can help students clarify nebulous points and reinforce proper interpretation of course information. Furthermore, in TL delivery oftentimes of S2II can occur in a face-toface or physical meeting, while in BL delivery S2II must be transmitted by electronic means, such as chat discussions, course messages, and e-mail communications. Ref [11] (p. 104) stated that S2II refers to the interaction between the learner and the instructor. This can take the form of instructor delivering information, encouraging the learner, or providing feedback. In addition, this can include the learner interacting with the instructor by asking questions, or communicating with the instructor regarding course activities. Ref [28] (P. 657), said there is a lack of close interaction between students. But the study did not manage the relationship between students and instructors in online participation. This study attempts to explain the importance of the two forms of interaction. The first interaction allows students to communicate with their instructors through SMS services or course messages in order to obtain timely information from their instructors as well as to help them exchange ideas and share information in the particular subject area. In addition, interactions allow students to discuss their topics through discussion forums or course messages.

Ref [29] indicates that students and instructors can benefit from the additional channel of communication such as SMS in the classroom, which implicitly points out individual learning experiences. The open channel turned out to be especially useful, efficient and preferred method of communication, in comparison to the traditional raising hands method of asking questions. The second interaction allows instructors to solve students' learning problems and respond immediately to their questions. Finally, this study attempts to investigate the effect of S2II when collaborative learning is added as a moderating variable between these interactions and SAP. Ref [13] identified five types of student-instructor interactions that are most predictive of students' sense of community. These interactions include: instructor modeling, support and encouragement, facilitating discussions, multiple communication modes and required participation. All these types of communications are important to students and will reflect on their academic performance. In the Journal of Computer Assisted Learning, Ref [30] found that factors related to instructional interaction had more predictive power on learners' perceived learning achievement than factors related to social interaction. He added that factors related to instructional interaction and presence of in- 
structor had more predictive power on learners' perceived satisfaction than factors related to social interaction.

The effect of student-to-content interaction on SAP - The objective of the S2CI is to study the interaction between students and course content found in BLP in order to examine to what extent the S2CI contributes to SAP. S2CI includes recorded videos, audio lectures, PowerPoint slides, written documents and group discussion. Ref [11] (p. 104) stated that S2CI is the method by which students obtain information from the course materials. The content can either be in the form of text, audio or videotape, CD-ROM, computer program, or online communication. Ref [14] stated that S2CI was found to be a significant predictor of student satisfaction and had a larger effect on the achievement of learning outcomes when compared to the effects of S2SI and S2II. The lack and weakness of interaction with course content was a commitment to promoting only one type of interaction. To make S2CI have positive impacts on SAP one need to integrate the three types of interactions in distance education.

Ref [31] carried out a study on the use of modern technology from student to student and across various groups in examining the relationship of BL in SAP. The findings suggested that students in multiple cohorts performed significantly better on multiple-choice questions that were accompanied by online resources. In addition, the use of online resources by students indicated that the high level of students to participate in online resources after the live teaching event. Ref [32] carried out research on the evaluation of BL in higher education at the Arab Open University of Kuwait. Their research indicated that the university is even more inclined towards TL than the e-learning education system. The author suggested that increasing e-content in college can help to have a balance between TL and BL in college. This study attempts to investigate the effect of student interaction with BL content compared to TL environments and how this interaction affects their academic performance (AP). Ref [23] stated that online examinations and electronic testing of LMS had a significant effect on SAP. This study uses both resources and online tutorials on LMS and traditional resource activities. These activities help students review and review the course content. Therefore, content availability will improve student interaction and will be reflected in your AP. This study concluded that student interaction with content will provide instructors with the ability to document students' performance levels on subjects. It also allows the instructor to review and update the topic on time.

Ref [33] conducted its study on the impact of multiple e-learning resources on SAP. Their findings showed that student interaction with the use of electronic resources and tools provided by instructors have a positive correlation with student ratings. In addition, they added that using the task management system and LMS, they contain resources and activities that encourage students to devote their time to tasks. It also solves problems of interaction with course content and interaction with each other. These systems have the most significant positive effects on grade performance. This study seeks to find the correlation between student interaction with content and SAP. Ref [28] stated that greater activities on the use of BLS will result in a better AP in terms of module degree. This means that students who completed all of their online activities using BLS will get high marks on their final exam. Therefore, this is reflected in your AP. Major BLS activities or assignments make the interaction of the stu- 
dent definitely difficult. However, the diversity of online activities will reduce student boredom. Therefore, this study attempts to use LMS activities such as assignments and electronic tests to improve practical aspects. The improvement of practical aspects will result in higher scores in student scores that will be reflected more in their AP.

Ref [34] indicated that interaction with content has statistically significant relationships between the amount of time the learner spent with the content and weekly quiz grades. She added in her conclusion, that the learners who spent more time interacting with course content achieve higher grades than those who spent less time with the content. This study attempts to find the correlation between student - content interaction and SAP.

The effect of student-to-blackboard interaction on SAP - The objective of S2BI is to investigate the interaction between students and blackboard learning platform (BLP) and its significances on SAP. S2BI is intended to enable students to master their interaction with BLP platform in which course content is used. In BL, the interaction concerns the technological media that allows students to interact with course content, instructor and other learners. In TL, students interact with various technologies such as audio, video conferencing, internet and e-mail.

Ref [35] (P. 213) and Ref [9], studied the effect of e-learning tools on SAP. Their findings revealed that the ease of use of learning tools will lead to improvement in academic performance. This study assumed that the interaction of students with ease of use of BLP will increase students' motivation to participate effectively through well-designed courses. Also, the interaction with BLP allows the instructor to design and prepare e-activities in a way that helps the students to understand their subject. Ref [36] stated that there is a lack of coordination of group involvement and the time management in some practical aspects which represent a key factor for student's success. Whenever student's time is saved, student's involvement as teamwork will appear. This means when the rate of student's acquisition of knowledge increased, SAP will improve. This study attempts to study the effect of student's interaction with the BLP and how this interaction affects their academic performance. In addition to that, this study also attempts to find the correlation between S2BI and SAP.

The effect of collaborative learning on SAP - The objective of using collaborative learning as a mediator variable is to find the effect of the predictor variables of interactions on SAP when CL mediates the indirect effects of predictors and SAP.

Ref [37] confirmed that CL is described as working together toward a common goal. This means that students are responsible for each other's learning as well as their own race. Reaching the goal implies that students have helped each other to understand and learn their subject in a collaborative way. Ref [9] indicated that synchronous communications, such as chat and conference require the presence of "physical" or "virtual" participants at the same time. This has the benefit of collaboration in realtime and delays in communication. Asynchronous communications, such as e-mail, blogs, and threads, have the advantage of allowing students to access learning resources at any time. Asynchronous communication mode is useful when learning parties have to communicate and share information between interaction sessions. 
Asynchronous is also beneficial when students are geographically dispersed and difficult to assemble at the same time.

\subsection{The influence of student characteristics on SAP}

The objective of this section is to review the characteristics of students that have a major effect on both TL and BL domains. Ref [18] listed the student characteristics factors in ability, motivation, attitude, and effort.

The effect of student ability on SAP - Refs [15, 18, 38, 39] using the information from variable proxies such as Skill including, Average High School Average, University GPA, Scholastic Aptitude Test (SAT) and Variable test tips. Their results showed that the proxy variables have a positive and significant effect on the test results. Therefore, it is reflected in SAP. The reported results supported by Ref [18], which confirmed that student ability accounts for large amounts of unique variance in college grades due to their relative independence from SAT and GPA scores for the high school. In addition, the results indicate that, after controlling the unobservable characteristics of students, teaching has an important independent effect on learning. Therefore, the student's ability is directly associated with SAP.

The effect of student motivation on SAP - Ref [39] stated that the motivation and attention problems most likely to occur in the larger classes. The attention problem affects student characteristics and leads to the low motivation. Ref [17] explained that absenteeism has proven to be an indicator of the low level of motivation for learning. In addition, a university culture that promotes discipline and integrity, especially among medical and older students, discourages social drug use likely to improve motivation. In addition to that, motivation is important for better academic performance.

The effect of student attitude on SAP - Ref [40] carried out research on students' attitudes in terms of examining the class attendance factor. The result showed that student attitudes toward lectures vary widely, from "never miss" to "are not worth anything", with most of the answers falling somewhere in between. Most students reported that they try to attend conferences, and often do so, occasionally losing them as a result of academic, extracurricular, or personal conflicts. Student responses showed that they are more willing to attend classes when instructors clearly teach with the help of appropriate examples and demonstrations. In addition, their interest in attending classes increases as teachers make an effort to align the content of the conference with the assessment requirements. The Refs [16, 18] emphasized that student performance is associated with the profile of students as their attitude towards the class. The student's attitude was found a critical factor that has a great contribution to SAP. Ref [23] in their results indicated that activities such as online tutorials had a significant effect on SAP, but feelings of isolation in the online environment represent an obstacle affecting the students' attitude to online activities. 


\subsection{The influence of class characteristics on SAP}

According to the literature, researchers of the same domain are emphasizing the effect of the characteristic factors of the class in SAP. Ref [41] states that the characteristic factors of the classes include learning activities, preferences and learning styles, course content and course evaluations. These factors have an impact on SAP measurement. Ref [42] found out that the impact of traditional learning on SAP is influenced by many internal and external variables. These variables have a positive or negative relationship with SAP.

Internal class factors (ICF) - Ref [5] groups the ICF in the student's English proficiency, class schedules, class size, English textbooks, test results of class, learning and style facilities, homework, classroom environment, the complexity of course material, the technology used in class systems and exams. These ICFs are very important to be considered when measuring SAP in mixed and traditional deliveries.

The effect of student learning on SAP - Ref [43] emphasized that teaching has a positive impact on student learning. In addition, an early study led by Ref [38] suggested that compulsory attendance could have a negative effect on student learning. On the other hand, another study conducted by Ref [44] stated that the strongest predictor of student learning was a previous academic success as measured by the current GPA of students. Therefore, all these factors dominate students to attend classrooms and laboratories and are reflected in their academic performance.

The effect of learning environment on SAP - Ref [16] stated that the disagreeable classroom environment makes it uncomfortable and the annoying teacher is associated with SAP. Uncomfortable environment not only impedes academic achievement but also promotes a poorly educated society and therefore leads to many negative social issues. This result was defended by Ref [15], which indicated that students from the SIMAD University (SU) were heavily affected by the SU environment. Also, Ref [17] in their conclusions showed that there is an extensive literature indicating the link between SAP and unfavorable learning environment.

The effect of time and marks allocation on SAP - Ref [16] stated that student performance is associated with the profile of students as the time allocation of studies. Ref [15] confirmed that students at the SIMAD University were greatly affected by the Marks assignment.

External class factors (ECF) - Ref [5] stated that there are ECFs that contribute in affecting SAP which is grouped by S N. K. Mushtaq in extracurricular activities, family problems, work, financial, social problems. Therefore, this study focuses on mainly family, work and health variables.

The effect of family variables on SAP - Ref [45] stated that parental involvement and family education affects student achievement. This finding supported by Ref [16] noted that student performance on the annual examination is associated with family income, education of mothers and fathers. They added that the factor such as mother's education has a positive impact on SAP. Ref [5] confirmed that family variables such as stress, social economic status, qualification, and responsibility are associated with SAP. 
The effect of job variables in SAP - Ref [17] indicated that $20 \%$ cited part-time work as the reason they lost many classes. Also, they are arguing that part-time and full-time construction is one of the main reasons for the lack of conferences. Therefore, a missed conference can be reflected in SAP.

The effect of health variables on SAP - Ref [45] indicated that student behavioral disorders are a key risk factor for substance use and psychiatric disorders. In addition, Ref [17] confirmed that, the association of socio-demographic student behavior. Therefore, the variables indicated affects the learning outcomes and are reflected in SAP.

\section{Discussions}

After a critical review of this study, the identified factors that have great influence on SAP have been discussed in term of proposed solutions and challenges.

\subsection{Technology use}

Refs $[6,31,46]$ proposed solutions of the use of technology in term of multimedia by posting an array of multimedia materials to support learners during their studies. This proposed solution has proved that multimedia sources have a major effect on SAP. The challenge of their solution will lead learners to use other digital media for entertaining instead of focusing on their learning materials. Also, Refs [7-9, 23, 47] suggested a solution of the use of technology in term of applications by using a webbased forum, features of LMS and e-learning tools. These proposed solutions have indicated that the use of these applications have major effects on SAP. The challenge encountered by learners in the proposed solutions will provide learners with a feeling of isolation during their interaction on the use of the stated applications. This challenge may lead to ineffective use of the stated technology which will reflect negatively on SAP.

\subsection{Interaction process}

Refs [7, 28] suggested that interaction through discussion forums and course messages can close the gap of the feeling of isolation during student interaction about the use of application technology. The challenge of this solution is that students lack close interaction with their instructors. References [47, 48] suggest that the instructor can provide a variety of activities within the lessons. This suggestion has its consequence on expectations of student performance. The challenge of this suggestion may result in the lack of feedback from the instructors. Refs [21, 23, 28, 33, 41, 49] proposed the solution to increase the e-content in the university that can help to provide a balance between the interaction of traditional learning and e-learning. They added that the number of activities will lead to a better academic performance in terms of module level. This solution represents the main challenges for students to prepare and control their activities. These challenges reported in a large number of activities will 
hinder student interaction, student attendance; will promote boredom and frustration. Ref [17] suggests that the use of resources that are available at LMS encourages students to devote their time to homework. This suggestion will result in a positive effect on the grade performance and will affect the final grade that will be reflected in SAP. The refs $[8,9,36]$ suggest that the interaction of students with the ease of use of the Blackboard learning platform (BLP) will increase students' motivation to participate effectively through well-designed courses. The ease of use of BLP will improve SAP. The challenge of this suggestion can lead to a lack of coordination of group participation and lack of time management. Ref [9] confirms that asynchronous communication allows students to access learning resources at any time without location restrictions.

\subsection{Student characteristics}

Refs [15, 38, 39] suggested that the ability of student to have high university GPA or pass scholastic aptitude test (SAT) and test tips scores have a positive and significant effect on the test results. The result of this suggestion is confirmed by Ref [18] which stated that student ability accounts for large amounts of unique variance in college grades due to their relative independence from SAT and GPA scores for the high school. The challenge of this suggestion will provide students inability to pass their final grades in BL since students experience lack of coordination of group involvement. Moreover, Ref [17] stated that a university culture that promotes discipline and integrity especially among students will likely improve their motivation in the online community. The Low level of motivation from staff members to students will result in a negative effect on SAP. Furthermore, Refs [16, 18] suggested that students attitude towards academic, extracurricular, or personal conflicts will reflect a negative effect on SAP. This challenge will result in students' performance and be reflected in their participation.

\subsection{Class characteristics}

There are many challenges of class characteristics that influence SAP. These challenges are classified into internal and external challenges that prevent students to enhance their academic performance. The authors of Refs [15-17, 41] classified the internal challenges into unpleasant classroom environment of TL and uncomfortable learning environment of BL, Timetable schedule, and clashes and marks distribution. Other authors of Refs $[5,17,50]$ listed the external challenges as family stress, socioeconomic status, level of education, parental involvement, missing classes and class absenteeism. All the internal and external challenges reflect negatively on the improvement of students' performance in both TL and BL deliveries. 


\section{$4 \quad$ Limitations}

The identified factors that influence on SAP have limitations which are classified into technical and pedagogical limitations. All factors and limitations are discussed briefly.

\subsection{Technical Limitations of BL and TL Domains}

Ref [51] stated that the limitations of the online environment are represented in the communication channels between the learner and the instructor. These channels do not have readily predictable responses because of the variability of the traffic load. In addition, the actual delay of these channels will depend on the configuration of the network, the bandwidth, the routing and the traffic at that moment. On the other hand, Ref [52] explained that, poor internet connection in traditional classrooms that made participants quickly frustrated and stop using online activities. In addition, Refs[53, 54] emphasized that the accessibility limitations of online activities are listed in communication with other online students and the trainers were not standardized resulting in some dissatisfaction as illustrated by students in the sessions. In addition, there is an absence of delay in feedback from remote tutors and citing problems with the use of technology. In addition, Ref [55] stated that there is a lack of communication with remote instructors to solve demanding learning problems. All of these problems are represented by critical technical constraints that influence SAP. Ref [56] summarized the barriers of instructors in using technology into lack of confidence, anxiety regarding the computer, resistance to and negative attitudes towards changes are considered internal barriers. The external barriers are listed as lack of access to the resources, lack of time, lack of instructors' competence and technical problems. There are other barriers to be considered, such as the educational system itself, which often limits innovative strategies regarding ICTs, due to its rigid and uncompromising structure. There is a shortage of physical adequacy for the incorporation of ICTs in the classrooms; there is a lack of software that contemplates the educational curriculum. In addition to obtaining the technology itself, instructors need to be trained to learn how to use all their resources appropriately.

\subsection{Pedagogical Limitations of BL and TL Domains}

Some pedagogical limitations that are preventing students from improving their academic performance are illustrated by many researchers such as Refs [52, 57-60], these limitations are reported in the student's lack of participation in the online environment, as well as, virtual classrooms. On the other hand, some online environments lack proper integration in a common framework. In addition, some students require more training and background in using the online environment. In addition to that, there is a lack of learning environment when using combined courses that are based on LMS. Finally, the lack of interaction process between the students in discussion and with their fellow students and tutors. 
Some researchers, such as Refs [23, 40] listed several limitations of online conferences in (a) decreasing student attendance in terms of face-to-face conferences that reduce student participation and performance. (b) Students will be reluctant to attend as online conferences are available twenty-four hours. Ref. [61] enumerated some limitations of $\mathrm{BL}$ in the tentative results of the students. In addition, for some students, it is the first time they experience BL. On the other hand, students were not mentally or cognitively prepared to adapt to the new mode of learning, which affects students' motivation and learning achievements. Ref. [1] established other limitations represented in the deficiencies of traditional and web-based learning. The inefficiency of the processes of student participation and interaction, a limited period of interaction between students and other students and instructors. There are some limitations of TL that affect the learning process. These limitations are represented for the management of online courses, the frustration of the students and the high drop-out rates of some experience. In addition, the limitations of TL, such as class time, the theme of the conference, the commitment of the staff and the interesting session, represent the main challenges of the learning process.

\section{Conclusion}

This work has shown the most important factors influencing SAP in two different domains of BL and TL. These factors are classified into four main categories. The first category represents the use of technologies in BL and TL that include multimedia and applications technologies. The second category is interaction processes that include student interaction, instructor interaction, content interaction, blackboard interaction and collaborative learning. The third category is student characteristics that include ability, motivation, and attitude.

The final category is class characteristics that consist of internal and external class factors. Internal class factors are represented in student learning, learning environment, time allocation, and markings. External class factors are represented by family variables, labor variables, and health variables. The technical limitations are represented into three challenges: the challenge of communication channels and poor internet connection. Future studies require enhancing infrastructure environment, the challenge of accessibility of online activities, to solve this challenge the authors suggest the diversity of online activities by giving learners one activity per week and the challenge of delays in feedback from remote instructors can be resolved by two forms of interaction between learner and instructor. The pedagogical limitations are represented into two challenges: challenges in day class time, conference theme, staff engagement level and interesting session, the challenge of proper integration in a common framework and standard integration framework requires integrating all online environments. 


\section{References}

[1] I. Y. Kazu and M. Demirkol, "Effect of Blended Learning Environment Model on High School Students' Academic Achievement," TOJET: The Turkish Online Journal of Educational Technology, vol. 13, 2014.

[2] C. C. Chen and K. T. Jones, "Blended Learning vs. Traditional Classroom Settings: Assessing Effectiveness and Student Perceptions in an MBA Accounting Course," Journal of educators online, vol. 4, p. n1, 2007.

[3] T. T. York, C. Gibson, and S. Rankin, "Defining and measuring academic success," Practical Assessment, Research \& Evaluation, vol. 20, p. 2, 2015.

[4] N. Oye, N. Iahad, M. Madar, and N. Rahim, "The impact of e-learning on students' performance in tertiary institutions," International Journal of Computer Networks and Wireless Communications, vol. 2, pp. 121-130, 2012.

[5] S. N. K. Mushtaq, "Factors affecting students' academic performance," Global Journal of Management and Business Research, vol. 12, 2012.

[6] P. R. Burden and D. M. Byrd, Methods for effective teaching: Meeting the needs of all students: Pearson, 2015.

[7] R. Nair and R. Patil, "A Study on the Impact of Learning Management Systems on Students of a University College in Sultanate of Oman," 2012.

[8] E. Galy, C. Downey, and J. Johnson, "The effect of using E-learning tools in online and campus-based classrooms on student performance," Journal of Information Technology Education: Research, vol. 10, pp. 209-230, 2011. https://doi.org/10.28945/1503

[9] N. A Iahah, "The impact of e-learning on students performance in tertiary institutions," International Journal of Computer Networks and Wireless Communications, vol. 2, pp. 121$130,2012$.

[10] K. Downing, K. Shin, and F. Ning, "Patterns of Interaction in Online Learning," Developing and Utilizing E-Learning Applications, vol. 84, 2010.

[11] A. Sher, "Assessing the relationship of student-instructor and student-student interaction to student learning and satisfaction in a Web-based online learning environment," Journal of Interactive Online Learning, vol. 8, 2009.

[12] K. L. Koskey and S. N. K. Benson, "A review of the literature and a model for scaffolding asynchronous student-student interaction in online discussion forums," Handbook of Research on Innovative Pedagogies and Technologies for Online Learning in Higher Education, p. 263, 2016.

[13] J. L. Shackelford and M. Maxwell, "Contribution of learner-instructor interaction to a sense of community in graduate online education," Journal of Online Learning and Teaching, vol. 8, p. 248, 2012.

[14] S. Chan and D. Bose, "Engage Online Learners: Design Considerations for Promoting Student Interactions," in Student Engagement and Participation: Concepts, Methodologies, Tools, and Applications, ed: IGI Global, 2017, pp. 96-118.

[15] A. A. Aden, Z. A. Yahye, and A. M. Dahir, "The Effect of Student's Attendance on Academic Performance: A Case Study at Simad University Mogadishu," Academic Research International, vol. 4, p. 409, 2013.

[16] A. Raychaudhuri, M. Debnath, S. Sen, and B. G. Majumder, "Factors affecting students' academic performance: A case study in Agartala municipal council area," Bangladesh. eJournal of Sociology, vol. 7, pp. 34-41, 2010.

[17] A. A. Desalegn, A. Berhan, and Y. Berhan, "Absenteeism among medical and health science undergraduate students at Hawassa University, Ethiopia," BMC medical education, vol. 14, p. 1, 2014. 
[18] M. Credé, S. G. Roch, and U. M. Kieszczynka, "Class attendance in college a metaanalytic review of the relationship of class attendance with grades and student characteristics," Review of Educational Research, vol. 80, pp. 272-295, 2010. https://doi.org/10.3102/0034654310362998

[19] V. Muniasamy, I. M. Ejalani, and M. Anandhavalli, "Moving towards virtual learning clouds from traditional learning: Higher educational systems in India," International Journal of Emerging Technologies in Learning (iJET), vol. 9, pp. 70-76, 2014. https://doi.org/10.3991/ijet.v9i9.4183

[20] Y. Li, M. Zhang, C. J. Bonk, and Y. Guo, "Integrating MOOC and Flipped Classroom Practice in a Traditional Undergraduate Course: Students' Experience and Perceptions," International Journal of Emerging Technologies in Learning, vol. 10, 2015.

[21] P. Andersen, What is Web 2.0?: ideas, technologies and implications for education vol. 1: JISC Bristol, UK, 2007.

[22] N. H. El-Khalili and H. El-Ghalayini, "Comparison of Effectiveness of Different Learning Technologies," International Journal of Emerging Technologies in Learning, vol. 9, 2014.

[23] A. Williams, E. Birch, and P. Hancock, "The impact of online lecture recordings on student performance," Australasian Journal of Educational Technology, vol. 28, pp. 199-213, 2012. https://doi.org/10.14742/ajet.869

[24] J.-H. T. Heng-Li Yang, "Effects of social network on students' performance: a web-based forum study in Taiwan," Journal of Asynchronous Learning Networks, vol. 7, pp. 93-107, 2003.

[25] R. Faizi, R. Chiheb, and A. El Afia, "Students' Perceptions Towards Using Web 2.0 Technologies in Education," International Journal of Emerging Technologies in Learning, vol. 10, 2015.

[26] H. L. Lim, "Understanding Group Interaction and Knowledge Building in Virtual Learning Environments," in Handbook of Research on E-Learning Applications for Career and Technical Education: Technologies for Vocational Training, ed: IGI Global, 2009, pp. 312-328. https://doi.org/10.4018/978-1-60566-739-3.ch025

[27] N. Tapsis and K. Tsolakidis, "Educational communication in virtual worlds and video conference," International Journal of Emerging Technologies in Learning (iJET), vol. 9, pp. 64-69, 2014. https://doi.org/10.3991/ijet.v9i9.4190

[28] J. Davies and M. Graff, "Performance in e-learning: online participation and student grades," British Journal of Educational Technology, vol. 36, pp. 657-663, 2005. https://doi.org/10.1111/j.1467-8535.2005.00542.x

[29] E. Scornavacca, S. Huff, and S. Marshall, "Understanding the value of interactive SMS for large classes," Innovative Mobile Learning: Techniques and Technologies: Techniques and Technologies, 2008.

[30] M. Kang and T. Im, "Factors of learner-instructor interaction which predicts perceived learning outcomes in an online learning environment," Journal of Computer Assisted Learning, vol. 29, pp. 292-301, 2013. https://doi.org/10.1111/jcal.12005

[31] N. P. Morris, "Blended learning approaches enhance student academic performance," in Proceedings of Enhancing Learning Experiences in Higher Education: International Conference, 2010.

[32] N. Zaeri, "Blended Learning System Performance Evaluation," International Journal of Computer Applications, vol. 76, 2013.

[33] R. Burk, Lyons, P., Noriega. A., \& Polovina-Vukovic, D, "The Impact of Multiple Electronic Learning Resources on Student Academic Performance," Toronto: Higher Education Quality Council of Ontario., 2013. 
[34] T. D. Zimmerman, "Exploring learner to content interaction as a success factor in online courses," The International Review of Research in Open and Distributed Learning, vol. 13, pp. 152-165, 2012. https://doi.org/10.19173/irrodl.v13i4.1302

[35] E. Galy, C. Downey, and J. Johnson, "The effect of using e-learning tools in online and campus-based classrooms on student performance," Journal of Information Technology Education, vol. 10, pp. 210-230, 2011. https://doi.org/10.28945/1503

[36] A. Targowski and A. M. Metwalli, Information technology and societal development: Information Science Reference Hershey, 2009.

[37] M. Dooly, Telecollaborative language learning: A guidebook to moderating intercultural collaboration online: Peter Lang, 2008.

[38] K. Adair and O. H. Swinton, "Lab attendance and academic performance," ISRN Education, vol. 2012, 2012.

[39] J. L. Caviglia-Harris, "Attendance and achievement in economics: Investigating the impact of attendance policies and absentee rates on student performance," Journal of Economics and Finance Education, vol. 4, pp. 1-15, 2006.

[40] T. Clay and L. Breslow, "Why students don't attend class," Available from: http://www. web. mit. edu/fnl, vol. 184, 2006.

[41] E. Osika, R. Johnson, and R. Butea, "Factors influencing faculty use of technology in online instruction: A case study," Online Journal of Distance Learning Administration, vol. 12, 2009.

[42] S. S. Bawaneh, "The effects of blended learning approach on students' performance: Evidence from a computerized accounting course," Interdisciplinary Journal of Research in Business, vol. 1, pp. 43-50, 2011.

[43] L. Stanca, "The effects of attendance on academic performance: Panel data evidence for introductory microeconomics," The Journal of Economic Education, vol. 37, pp. 251-266, 2006. https://doi.org/10.3200/JECE.37.3.251-266

[44] J. J. Bethune, "Attendance, grades and learning in the microeconomic principles class," Journal of Economics and Economic Education Research, vol. 11, p. 53, 2010.

[45] C. A. Kearney, "School absenteeism and school refusal behavior in youth: A contemporary review," Clinical psychology review, vol. 28, pp. 451-471, 2008. https://doi.org/10.1016/ j.cpr.2007.07.012

[46] H. Collins, Creative research: the theory and practice of research for the creative industries: Ava Publishing, 2010.

[47] T. Wang and C. Hsu, "The Impact of Board Structure on Information Security Breaches," in PACIS, 2010, p. 165.

[48] R.-A. Lee and B. Dashew, "Designed Learner Interactions in Blended Course Delivery," Journal of Asynchronous Learning Networks, vol. 15, pp. 68-76, 2011. https://doi.org/10.24059/olj.v15i1.183

[49] M. Wieling and W. Hofman, "The impact of online video lecture recordings and automated feedback on student performance," Computers \& Education, vol. 54, pp. 992-998, 2010. https://doi.org/10.1016/j.compedu.2009.10.002

[50] W. Fan and C. M. Williams, "The effects of parental involvement on students' academic self-efficacy, engagement and intrinsic motivation," Educational Psychology, vol. 30, pp. 53-74, 2010. https://doi.org/10.1080/01443410903353302

[51] C. Salzmann, D. Gillet, H. A. Latchman, and O. D. Crisalle, "On-line engineering laboratories: real-time control over the Internet," age, vol. 4, p. 1, 1999.

[52] A. Sagun, H. Demirkan, and M. Goktepe, "A Framework for the Design Studio in WebBased Education," Journal of Art \& Design Education, vol. 20, pp. 332-342, 2001. https://doi.org/10.1111/1468-5949.00282 
[53] M. Cooper, "Remote laboratories in teaching and learning-issues impinging on widespread adoption in science and engineering education," International Journal of Online Engineering (iJOE), vol. 1, 2005.

[54] I. Gustavsson, J. Zackrisson, L. Håkansson, I. Claesson, and T. L. Lagö, "The visir project-an open source software initiative for distributed online laboratories," in REV 2007, 2007.

[55] K. F. Hew and W. S. Cheung, "Students' Use of Asynchronous Voice Discussion in a Blended-Learning Environment: A Study of Two Undergraduate Classes," Electronic Journal of E-Learning, vol. 10, pp. 360-367, 2012.

[56] R. F. Esteves, S. H. Fiscarelli, and J. L. Bizelli, "Interactive Whiteboards in Brazilian's Primary School: New Barriers," International Journal of Emerging Technologies in Learning, vol. 10, 2015.

[57] J. Williams and M. Fardon, "Recording lectures and the impact on student attendance," ALT-C, September, pp. 4-6, 2007.

[58] A. Böhne, N. Faltin, and B. Wagner, "Synchronous tele-tutorial support in a remote laboratory for process control," Innovations, pp. 317-329, 2004.

[59] W. Nejdl and M. Wolpers, "European e-Learning: Important research issues and application scenarios," in World Conference on Educational Multimedia, Hypermedia and Telecommunications, 2004, pp. 2054-2068.

[60] A. Heirdsfield, S. Walker, M. Tambyah, and D. Beutel, "Blackboard as an online learning environment: What do teacher education students and staff think?," Australian Journal of Teacher Education (Online), vol. 36, p. 1, 2011. https://doi.org/10.14221/ajte.2011v36n7.4

[61] Z. Li, M.-H. Tsai, J. Tao, and C. Lorentz, "Switching to blended learning: the impact on students' academic performance," Journal of Nursing Education and Practice, vol. 4, p. 245, 2014. https://doi.org/10.5430/jnep.v4n3p245

\section{Authors}

Ahmed O. A. Ismail is a lecturer at Faculty of Science and Arts at King Khalid University, Mohayel, Saudi Arabia. Ph.D. student at Universiti Teknologi PETRONAS, Bandar Seri Iskandar, Malaysia (e-mail: ibn_omer@hotmail.com; aesmeal@kku.edu.sa).

Ahmad K. Mahmood is an associate professor at the Faculty of Science and Information Technology at Universiti Teknologi PETRONAS, Bandar Seri Iskandar, Malaysia. (e-mail:kamilmh@petronas.com.my).

Abdelzahir Abdelmabouda is an assistant professor Faculty of Science and Arts at King Khalid University, Mohayel, Saudi Arabia (e-mail: aelnour@kku.edu.sa).

Article submitted 28 November 2017. Final acceptance 06 February 2018. Final version published as submitted by the authors. 